\title{
Research on the Current Situation and Countermeasures of Inventory Management of Xin Zhongkang PharmaceuticalCompany
}

\author{
Chun-Li LIU \\ Management School \\ Xinxiang Medical University \\ Xinxiang, China \\ chp0201@126.com
}

\begin{abstract}
With the continuous development of social economy, the pharmaceutical industry has gradually become an important part of social development, is an important project related to the development of the national economy and the people's livelihood. Economic progress to promote innovation in the pharmaceutical industry. However, from the overall situation of China's pharmaceutical industry, there are many serious problems. One of the most difficult is the pharmaceutical company's inventory management problems. At present, most of the pharmaceutical companies are using the traditional inventory management model, cannot occupy a favorable position in the market competition. Based on this, this paper analyzes the current situation of the inventory management of the Xin Zhongkang pharmaceutical company, and puts forward the Countermeasures of inventory management.
\end{abstract}

Keywords-Xin Zhongkang pharmaceutical company; inventorymanagement; countermeasures

\section{INTRODUCTION}

With the development of the social economy, the pharmaceutical industry is becoming an important part of social development, and it is an important project that concerns the development of national economy and people's livelihood. Economic progress is driving innovation in the pharmaceutical industry. However, there are many serious problems in the present situation of the pharmaceutical industry in China. One of the trickiest is the issue of inventory management at pharmaceutical companies.

At present, most of the pharmaceutical companies are traditional inventory management models that do not have a favorable position in market competition. Based on this, this paper analyzes the present situation of the inventory management of xinzhongkang pharmaceutical co., and puts forward the countermeasures to improve the inventory management.

\section{XIN ZHONGKANG PHARMACEUTICAL COMPANY PROFILE}

Xin Zhongkang is a wholesale, allocation, retail chain, distribution in one of the pharmaceutical business enterprise. The company engaged in medicine, chemical medicine preparations, antibiotics, biochemical drugs, biological products (except vaccines) and other more than 5 thousand varieties, has a business relationship with more than and 260 suppliers and more than and 400 customers, sales network to Xinzheng as the center, radiation Zhengzhou, Luoyang, Anyang, Xuchang, Zhoukou, Kaifeng, Shangqiu, Zhumadian and other regions, the total annual sales exceeded 100 million yuan, and in 2009, May and December respectively through the national GSP certification, November 2010 to obtain the basic drugs in Henan province distribution right. At present, the hospital has two cooperative hospitals of Henan hongda cardiovascular hospital, Xinzheng City People's Hospital, Xinzheng Second People's Hospital, Xinzheng city hospital, Xinzheng maternal and child health hospital, 8, in the business, companies with high standards and strict control of procurement, inspection, storage, sales and customer service service sectors. To ensure the quality of drugs, to provide safe and effective drugs of high quality to the customer and the masses of the people.

The company has a standardized warehouse area of 3731.3 square meters. Drug warehouse has three floors, one floor underground and two floors, of which the negative layer area and negative two area almost, nearly 2500 square meters, the main function is to hold a negative delivery and drugs are important for storage, and the turnover relatively short period of drug in order to facilitate the implementation of internal storage, drug delivery. In the negative two layers of relatively light quality of the drug storage and turnover of relatively long drugs. But the interior between floors is only 5 meters high, when the drug has seasonal inventory, warehouse space usage will be relatively tight, but in the actual process of drug handling, because the storage space is still using manual handling management form, the lower the degree of mechanization.

\section{INVENTORY MANAGEMENT OVERVIEW}

\section{A. Inventory Definition}

Inventory plays an important role in many types of enterprises, its essence is to meet the needs of the development of production and life in the future, and the corresponding space resources to make valuable tentative.

As the pharmaceutical retail chain enterprises, the drug inventory form according to the actual demand of stores, and take different types of service needs, at present, in general the pharmaceutical company in the main form of stock mainly in the following forms: 1 , type, floor type batch heap storage and automatic storage form, type 2; many small 
quantities of pallet rack storage form; 3, into the rack form; 4, goods shelves form format.

\section{B. Inventory Effect}

First, to deal with the unstable factors of pharmaceutical enterprises. For pharmaceutical companies, there are many uncertainties in the pharmaceutical business, such as changes in the demand for drug users, changes in drug suppliers, as well as changes in drug quality, etc.. The pharmaceutical company inventory can play a buffer role in these drug unstable factors, although uncertainty is difficult to control, but not because of the mutation of pharmaceutical enterprises facing significant economic losses.

Second, to achieve sales stability. The existence of inventory can cope with seasonal changes in the economic market. For example, in the spring and summer, when a high incidence of cold fever, for the type of drug needs to be stored in a rainy day. During the winter and Spring Festival, the demand for health care products is relatively high, therefore, the need to increase the corresponding category of drug stocks in advance.

Third, inventory can achieve commercial speculation. Drug prices are often affected by the economic market factors, and the existence of inventory can effectively deal with the changes in these factors to achieve stable drug supply.

\section{PROBLEMS EXISTING IN INVENTORY MANAGEMENT OF XIN ZHONGKANG PHARMACEUTICAL COMPANY}

\section{A. Inventory and Drug Sales Do Not Converge}

The most important problem in the pharmaceutical company's inventory management is that it cannot achieve the scientific docking between the sales and inventory. If the drug sales situation is not good, and a large inventory, it will enhance the cost of pharmaceutical companies, is not conducive to the actual operation of enterprises. Based on the analysis of drug inventory management reports in recent years, there are a lot of gaps between drug supply and drug inventory. For example, milianchuanbei Pipagao in 2014 the Xin Zhongkang pharmaceutical company (Nian Cian) inventory for 3369 bottles, because this type of drug belongs to pay amount type, so the inventory amount is 78975.62 yuan, if calculated in accordance with 100 boxes of daily sales, can draw the sales number of days to 34 days. But the type of drug sales there is a certain seasonal, in the winter sales faster, but in summer sales are relatively low. In the summer, due to the relatively large inventory of drugs, the higher the cost of arrival, hindering the economic operation of pharmaceutical companies.

B. Serious Backlog of Internal Drug Varieties

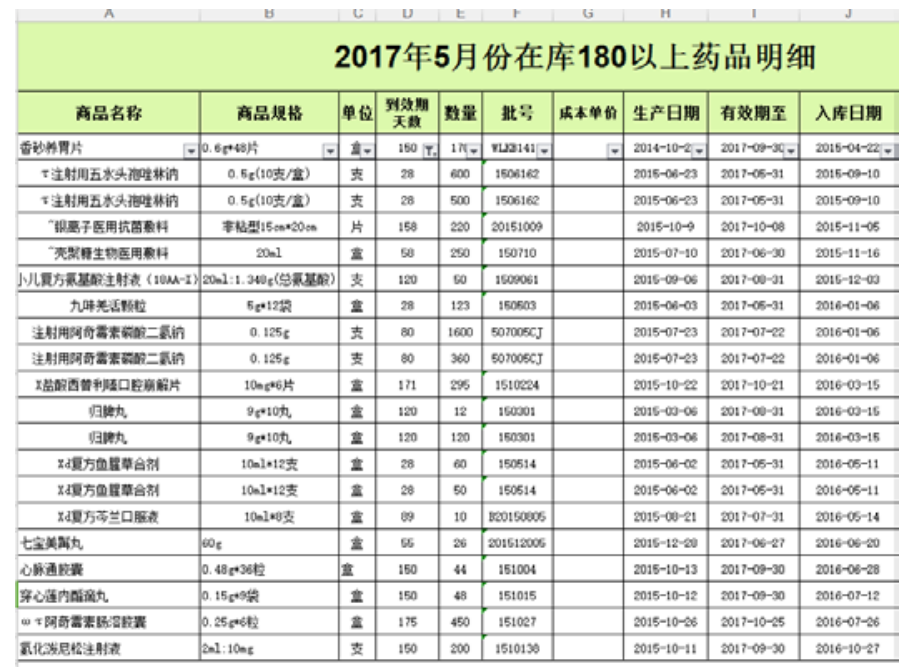

Chart - Within six months is about to expire varieties and quantity chart

(Source: company stock screenshot)

From the type of drug warehouse in May 2017, the Xin Zhongkang pharmaceutical company stores nearly 16 kinds of drugs will expire in the second half of this year, while the total cost of these drugs to more than 60 thousand, and these costs accounted for the total amount of the Xin Zhongkangpharmaceutical company's stock 8\%. Thus, the Xin Zhongkangpharmaceutical company's inventory management in the emergence of a serious problem, a large number of expired drugs can only be faced with the backlog of being terminated. But in the actual drug sales, many drugs will expire to transfer downstream suppliers in the phenomenon, this phenomenon not only have a negative impact on the drug company, on the other hand it also brings the risk of consumer life safety.(as shown chart)

\section{Drug Distribution Logistics Model Is Unscientific}

Xin Zhongkang pharmaceutical company to each new drug stores and distribution of drugs in many scientific aspects of place, because there is a great difference between the various drug retail stores, therefore, lead to different types of drug retail demand is not uniform, and the Xin Zhongkangpharmaceutical companies and the lack of scientific distribution plan, and lead to drug distribution randomness.

\section{XIN ZHONGKANG PHARMACEUTICAL COMPANYINVENTORY MANAGEMENT COUNTERMEASURES}

\section{A. Establishment of Drug Planning Management System}

In order to realize the scientific management of drug stock, first established category management system, to consumers as the center, the different categories of decomposition for the smallest unit set, so as to realize the maximum utilization of resources, and gradually enhance profit level of medicine. Category management model is widely used in the pharmaceutical retail industry, not only can effectively improve the performance of retail outlets, but also to achieve the drug inventory management. The 
management mode of this kind of model drugs compared with the traditional more standardized and scientific, in the digital information technology support, management of the warehouse in drug varieties, and the shelf space, and then realize the optimal combination of drug types, effectively improve the spatial resources, reduce inventory. The implementation of category management, first need to make reasonable planning of the drugs, and thus enhance the sales of goods, the main steps are: 1 , to determine the drug category and sub category; 2, for consumers to make purchase plan; 3 , to the consumer demand as the basis, to achieve category grouping; 4, market assessment, 5; implement marketing strategy.

\section{B. The Application of ABC Classification in the Inventory Management of Xin Zhongkang Pharmaceutical Company}

ABC classification is to classify the difference of drug pointer, the actual drug sales contribution and the proportion of stock, to develop a drug inventory management plan, as well as $\mathrm{B}$ and $\mathrm{C}$, among them a kind of the most critical drugs inventory of drugs, not out of stock of the situation, the medicine enterprises in this type of drug in the investment cost is relatively large, the funds rate is relatively high. In the new inventory management Kang pharmaceutical company, take the classification of ABC, can be the most key, secondary key inventory and key medicines, were screened out from many drug inventory, focusing on the type of drug management particularity, this method can be the original complex simple management mode. For the upcoming expiration, as well as the phenomenon of excess drug backlog, the use of ABC classification method, the drug can be sorted and sorted. In the classification before, according to the actual distribution of drugs in the pharmaceutical market to carry out inventory classification. In the actual implementation of the $\mathrm{ABC}$ classification, inventory managers need to be based on the different types of drugs in the warehouse of the control, management and storage conditions for the development of drugs cannot manage the program. Scientific management to optimize inventory management. For a class of drugs, inventory managers need to maximize the sales of these types of drugs only, in the stable drug market operation mode, the realization of market supply of drugs, and the realization of flexible drug turnover.

\section{Realization of Information Inventory Management}

\section{1) Inventory management with "three networks"}

Informatization is an important indicator of the modern logistics enterprises, many multinational logistics enterprises have"first-class network", "class" refers to the order information flow as the center; "three" refers to the global supply chain network resources, global user resources network and computer information network. All production enterprises can accept orders on the Internet, and through online query plan and inventory to timely replenishment; goods warehousing, logistics department according to the production plan, the use of ERP system for batching.

Xin ZhongkangPharmaceutical company should use information technology to integrate business processes, can be integrated into the customer's production and management process, the establishment of an"efficient trading" business management model. Enterprises should be two pronged grasping network construction: on the one hand, to establish the physical. According to the actual situation; on the other hand, the use of the Internet, MIS and EDI to construct the information system of invisible, real-time tracking, effective control and management of the logistics chain, a symbiotic relationship of interdependent markets. Through the realization of the network of internal resources, the sharing of information, the simplification of the transaction, thereby reducing transaction costs, enhance the competitiveness of enterprises.

\section{2) Vendor Managed Inventory}

Vendor managed inventory is managed by the supply chain of pharmaceutical production enterprises to manage the inventory of users in order to reduce the cost of the enterprise. For a long time, the pharmaceutical enterprises in the circulation of inventory management in their own way, production enterprises, wholesale enterprises and retail enterprises in order to cope with unpredictable user needs, each have their own inventory.

In this mode, we must first establish a standard order processing mode. Production enterprises and wholesale and retail enterprises with information to determine the necessary number of orders and inventory control business processes, establish a standard order processing mode after the order, delivery and bill processing business integration for manufacturers.

Secondly, the establishment of customer information system. In order to manage the inventory effectively, the manufacturer must be able to obtain the information of the customer in time. Through the establishment of customer information database, the production enterprises can promptly grasp the situation changes in demand, prediction and analysis functions previously performed by wholesale and retail enterprises to focus on the system of production enterprises, to ensure their products demand information and logistics.

Third to establish continuous replenishment program. Production enterprises should establish partnerships with the user, from the past simply execute the user purchase orders, to take the initiative to provide users sharing inventory responsibility in speeding up the production enterprises in response to user demand speed at the same time, allowing users to reduce inventory.

\section{SUMMARY}

Based on the analysis of the current situation of inventory management, this paper puts forward some countermeasures to improve inventory management. In order to realize the scientific management of the pharmaceutical industry, the first thing is to establish the management system of drug planning, with the application of the actual ABC classification in the management of Xin Zhongkang inventory as an example. Focus on the realization of information inventory management. 


\section{REFERENCES}

[1] IB Rosales, GV Sanchez, OS Vargas Inventory Management to Minimize Storage Costs and Improve Delivery Time in a Pharmaceutical Industry 2017

[2] M Mouaky, A Berrado, L Benabbou A Kanban based system for multi-echelon inventory management: The case of pharmaceutical supply chain . International Conference on Logistics Operations Management 2016

[3] B Jiang, L Teng Vendor Managed Inventory Integration on Pharmaceutical Third-party Logistics. International Journal of Multimedia and Ubiquitous Engineering .Vol.11, No.6 (2016), pp.397-410
[4] AR Vila-Parrish, JS Ivy, B. HeImpact of the Influenza Season on a Hospital from a PharmaceuticalInventory Management Perspective.Operational Research for Emergency Planning in Healthcare: 2016 Volume 1 Part of the series The OR Essentials series pp 249-287

[5] An Eriksson, E Zachrisson . Pharmaceutical Distribution in Japan. A study on how external factors affect the Japanese pharmaceutical wholesale industry.[D]2016

[6] PD Antoniolli - BBR - Brazilian B. Information Technology Framework for Pharmaceutical Supply Chain Demand Management: a Brazilian Case Study .BBR - Brazilian Business Review, vol. 13, núm. 2, marzo-abril, 2016, pp. 27-55 